\title{
Exocrine Pancreatic Insufficiency after Gastrectomy for Cancer Is Not Severe
}

\author{
Matthew J. DiMagno \\ Division of Gastroenterology and Hepatology, Department of Internal Medicine, University of Michigan School of \\ Medicine, Ann Arbor, MI, USA
}

Dear Editor,

I congratulate the authors of the Systematic Review of Exocrine Pancreatic Insufficiency (EPI) after Gastrectomy for Cancer [1]. The literature search identified 4 of 1,023 studies for review [2-5]. Overall, I agree with the authors' interpretation that EPI is common following total gastrectomy. Although the authors found that total exocrine pancreatic function decreases by as much as $76 \%$, they do not sufficiently emphasize that the degree of EPI is typically mild to moderate severity following total gastrectomy with duodenal continuity, and specifically not severe enough to cause pancreatic steatorrhea, which requires a $90 \%$ reduction (of lowest normal values) in lipase output $[6,7]$. Also, the authors did not include an older study investigating EPI following gastrectomy for cancer [8], which is worthy of consideration, particularly with the limited data available.

Critical points to interpreting the results of pancreatic function tests (PFTs) in post-gastrectomy patients are the use of accurate PFTs and the testing of patients with gastrointestinal continuity following gastrectomy. The most accurate PFTs were used in 2 studies [2,3] in the systematic review and in the additional study [8], each involving either secretagogue $[2,3]$ or testmeal [8] evoked direct PFT. All patients in the 3 studies had post-gastrectomy duodenal continuity of either jejunal interposition or esophagoduodenal anastomosis or jejunal pouch reconstruction.

In none of the 3 studies was EPI severe enough to cause steatorrhea, but it should be noted the sample size in each of the studies was very small, ranging 8-12 patients per study. Gullo et al. [2] performed secretin-cerulein stimulated direct PFT in normal controls and 12 patients following total gastrectomy with jejunal interposition or esophagoduodenostomy. Eight patients had gastric cancer. Gastrectomy patients had mild-moderate $(38 \%)$ reductions in stimulated lipase output versus controls, insufficient to cause pancreatic steatorrhea [6]. Not surprisingly, lipase outputs did not correlate with steatorrhea (present in 8 of 12) [2]. Friess et al. [3] performed direct secretin-cerulein stimulated PFT in 9 patients with gastric cancer, both preoperatively and 3 months after total gastrectomy with jejunal pouch. Following gastrectomy, median secretagogue-evoked juice values were reduced $72 \%$ for amylase (suggesting moderate EPI) and 89-91\% for trypsin and chymotrypsin (suggesting borderline severe EPI). Importantly, the authors calculated the reduction of enzyme values from the median rather than the lowest normal or lower quadrant values resulting in greater calculated reduction of enzyme secretion than was present. Further, the authors did not measure lipase outputs. Thus the severity of EPI in the Friess study would be most consistent with mild-moderate EPI, which alone would not cause steatorrhea. Fischermann et al. [8] performed test-meal evoked PFT in normal controls and 8 gastric cancer patients who had total gastrectomy and jejunal interposition. The gastrectomy group had only mild-moderate reductions in test-meal evoked peak lipase concentrations.

The most plausible single explanation for mild-moderate EPI following total gastrectomy for gastric cancer is denervation (truncal vagotomy and interruption of gastropancreatic nerves secondary to lymph
KARGER

(C) 2019 S. Karger AG, Basel

E-Mail karger@karger.com

www.karger.com/dsu
Matthew J. DiMagno, MD

Division of Gastroenterology and Hepatology, Department of Internal Medicine University of Michigan School of Medicine, 1150 W. Medical Center Drive 6520 MSRB 1, Ann Arbor, MI 48109-5362 (USA)

E-Mail mdimagno@med.umich.edu 
node dissection). Reduced outputs in patients following gastrectomy (above studies) are similar to those in patients following truncal vagotomy, which causes reductions of lipase and trypsin outputs by 53 and $61 \%[9,10]$. Onset of steatorrhea following gastrectomy is most likely attributable to non-pancreatic causes, particularly post-surgical anatomy without duodenal continuity (e.g., Rou-en-Y), causing a mixing disorder (asynchrony between delivery of pancreatic enzymes and chyme) and maldigestion. Pancreatic enzyme replacement therapy (PERT) can correct the mixing disorder, but this does not equate to a diagnosis of EPI.

In 2 PERT trials $[4,5]$, a placebo-controlled RCT [4] and a cross-over trial [5], steatorrhea and lack of responsiveness to PERT are attributable to post-surgical anatomy, PERT dosing and non-pancreatic factors rather than EPI. Bragelmann et al. [4] reported PERT (76,000 FIP units of lipase per meal) did not reduce steatorrhea compared to placebo. Armbrecht et al. [5] reported that PERT (120,000 units of lipase per meal) only reduced fecal fat excretion compared to placebo in the subset of patients with "massive" steatorrhea. These conflicting data are likely due to a higher frequency Rou-en-Y postsurgical anatomy in the Armbrecht vs Bragelmann studies (100 vs. $65 \%$ ) but also due to under-dosing of PERT in the Bragelmann study (see review of PERT dosing [7]), exclusion of small intestinal bacterial overgrowth in the Armbrecht but not Bragelmann study, or other factors that may have caused steatorrhea in Bragelmann study [4].

\section{Disclosure Statement}

M.J.D. received honoraria from the British Medical Journal Publishing Group Limited (for articles published in British Medical Journal Point-of-Care), Oakstone Publishing (for Podcasts on Pancreatic Disorders, Best of DDW 2013-2018),
American Gastroenterological Association Institute Council (for coauthoring a technical review on acute pancreatitis-2017), and The William M. Steinberg Board Review in Gastroenterology and Best Practices Course (for presentations on pancreatitis and pancreatic cystic neoplasms-2018). Dr. DiMagno received consulting fees from (i) the American College of Physicians (Philadelphia, PA, USA) for co-authoring 2 chapters in the Gastroenterology and Hepatology section of MKSAP 17 and (ii) Cystic Fibrosis Foundation Therapeutics, Inc. (Bethesda, MD, USA). M.J.D. declares no competing interests.

\section{Funding Sources}

Funds were received from NIH/NIAAA (R21AA017271) for the past 3 years; Cystic Fibrosis Foundation: Developing Innovative GastroEnterology Specialty Training Program.

\section{References}

1 Straatman J, Wiegel J, van der Wielen N, Jansma EP, Cuesta MA, van der Peet DL: Systematic review of exocrine pancreatic insufficiency after gastrectomy for cancer. Dig Surg 2017;34:364-370

2 Gullo L, Costa PL, Ventrucci M, Mattioli S, Viti G, Labo G: Exocrine pancreatic function after total gastrectomy. Scand J Gastroenterol 1979;14:401-407.

3 Friess H, Bohm J, Muller MW, et al: Maldigestion after total gastrectomy is associated with pancreatic insufficiency. Am J Gastroenterol 1996;91:341-347.
4 Bragelmann R, Armbrecht U, Rosemeyer D, Schneider B, Zilly W, Stockbrugger RW: The effect of pancreatic enzyme supplementation in patients with steatorrhoea after total gastrectomy. Eur J Gastroenterol Hepatol 1999; 11:231-237.

5 Armbrecht U, Lundell L, Stockbrugger RW: The benefit of pancreatic enzyme substitution after total gastrectomy. Aliment Pharmacol Ther 1988;2:493-500.

6 DiMagno EP, Go VL, Summerskill WH: Relations between pancreatic enzyme outputs and malabsorption in severe pancreatic insufficiency. N Engl J Med 1973;288:813-815.

7 DiMagno EP, DiMagno MJ: Chronic pancreatitis: landmark papers, management decisions, and future. Pancreas 2016;45:641-650.
8 Fischermann K, Harly S, Worning H, Zacho A: Pancreatic function and the absorption of fat, iron, vitamin B12, and calcium after total gastrectomy for gastric cancer. Gut 1967;8: 260-266.

9 Malagelada JR, Go VL, Summerskill WH: Altered pancreatic and biliary function after vagotomy and pyloroplasty. Gastroenterology 1974;66:22-27.

10 Wormsley KG: The effect of vagotomy on the human pancreatic response to direct and indirect stimulation. Scand J Gastroenterol 1972;7:85-91. 